\title{
Adubação Suplementar de Nitrogênio na Soja Via Solo e Foliar na Fase Reprodutiva
}

\section{Supplementary Nitrogen Fertilization in Soybean Via Soil and Leaf in the Reproductive Phase}

\author{
José Antonio Maior Bono*a; Talles Edmundo de Assis ${ }^{\mathrm{a}}$; André Luiz Araújo Martinellib
}

\author{
aUniversidade Anhanguera Uniderp, Programa de Pós-Graduação Stricto Sensu em Produção e Gestão Agroindustrial. MS, Brasil. \\ bUniversidade Anhanguera Uniderp, Curso de Agronomia. MS, Brasil, \\ *E-mail: bono@anhanguera.com
}

\begin{abstract}
Resumo
A planta de soja tem a associação simbiôntica com micro-organismos que têm a capacidade de fixar nitrogênio (N) e liberá-lo para as plantas. Nas cultivares de soja de alto potencial produtivo, a demanda por $\mathrm{N}$ estaria sendo atendida através da fixação biológica de nutrientes (FBN) ou haveria a necessidade de complementação deste nutriente para a cultura. Este trabalho teve como objetivo verificar a resposta da cultivar de soja Desafio inoculada com bactérias Bradyrhizobium japonicum e Bradyrhizobium elkanii, e com adubação nitrogenada suplementar na fase reprodutiva, via solo e via foliar. Os tratamentos constituíram da testemunha (sem aplicação de N), 30 e $60 \mathrm{~kg}$ de $\mathrm{N}$ ha ${ }^{-1}$ via solo e solução a $2 \%$ de $\mathrm{N}$ aplicados nas fases R1 e R5.3. O delineamento foi de blocos casualizados com quatro repetições e as sementes foram inoculadas com bactérias das espécies Bradyrhizobium japonicum e Bradyrhizobium elkanii (estirpes Semia 587 e Semia 5019). A aplicação tardia de N em R1 e em R5.3 proporcionou aumento na produtividade de grãos de 478,6 $\mathrm{kg} \mathrm{ha}^{-1}$ e $472,8 \mathrm{~kg} \mathrm{ha}^{-1}$, respectivamente. A aplicação via solo de $\mathrm{N}$ em R1 apresenta melhor índice de colheita, quando comparada com a R5.3. A aplicação tardia de solução de $2 \%$ de N, via foliar, não proporciona aumento na produtividade da cultura da soja.
\end{abstract}

Palavras-chave: Glycine max. Produtividade. Fixação Biológica. Adubação Nitrogenada.

\begin{abstract}
The soybean plant has the symbiotic association with microorganisms that has the ability to fix nitrogen $(N)$ and release it to the plants. Soybean cultivars with high productive potential, $N$ demand would be met through biological nutrient fixation (BNF) or there would be a need to complement this nutrient for the crop. The objective of this work was to verify the response of soybean inoculated with bacteria of the genus Rhizobium and Bradyrhizobium, the supplementary nitrogen fertilization in the reproductive phase, soil and leaf pathway. The treatments consisted of control (without application of $\mathrm{N}$ ), 30 and $60 \mathrm{~kg}$ of $\mathrm{N} \mathrm{ha} \mathrm{T}^{-1}$ via soil and $2 \% \mathrm{~N}$ solution applied in phases R1 and R5.3. The design was randomized blocks with 4 replications and the seeds were inoculated with bacteria of the species Bradyrhizobium japonicum and Bradyrhizobium elkanii (strains Semia 587 and Semia 5019). The late application of $N$ in R1 and R5.3 increased grain yield of $478.6 \mathrm{~kg}$ $h a^{-1}$ and $472.8 \mathrm{~kg} \mathrm{ha} 1$, respectively. The application, via soil, of $N$ in $R 1$ presents a better harvest index, when compared to R5.3. The late application of $2 \% \mathrm{~N}$ solution, via leaf, did not increase the soybean crop yield
\end{abstract}

Keywords: Glycine max. Productivity. Biological Fixation. Nitrogen Fertilization

\section{Introdução}

A demanda de nitrogênio da soja é suprida, principalmente, pela fixação biológica, por meio da simbiose das plantas com bactérias dos gêneros Bradyrhizobium e Rhizobium, sendo responsável por cerca de $90 \%$ do nitrogênio $(\mathrm{N})$ fixado de forma natural, o restante da demanda de nitrogênio seria suprido pelo solo por meio da mineralização da matéria orgânica. O N assimilado pela soja é exportado para os grãos, na forma de proteína, e o período de maior demanda ocorre entre os estágios R1 (início do florescimento) e R6 (máximo volume dos grãos) (MAEHLER et al., 2003).

A aplicação de $\mathrm{N}$ na semeadura pode trazer prejuízo no processo de simbiose (bactérias e planta), e foi demonstrado por Hungria et al. (2006) e Zilli et al. (2010) com aplicações na

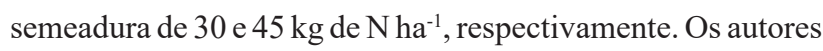
observaram redução da nodulação e contribuição da FBN (fixação biológica de nitrogênio), no total de $\mathrm{N}$ acumulado na parte aérea pelas plantas de soja e na produtividade. Franchini et al. (2015) não obtiveram resposta na produtividade da soja na aplicação de $30 \mathrm{~kg} \mathrm{ha}^{-1}$ de N. Werner et al. (2016), trabalhando com 0 e $34 \mathrm{~kg} \mathrm{~N} \mathrm{ha}^{-1}$, verificaram efeito da adubação nitrogenada no crescimento das plantas, contudo, não ocorreu aumento da produtividade.

O aumento da produtividade da soja, nos últimos anos, traz o questionamento quanto à inoculação e a matéria orgânica presente no solo, sendo capazes de atender toda a demanda da planta. Como a adubação de $\mathrm{N}$ na semeadura teria potencial prejuízo para a nodulação, deslumbra-se sua a aplicação tardia para o aumento da produtividade da cultura. Mendes et al. (2008), estudando a adubação suplementar tardia com nitrogênio na soja sob plantio direto, observaram que $50 \mathrm{~kg}$ $\mathrm{ha}^{-1}$ de N, na forma de sulfato de amônio aplicados em R5, apresentaram rendimentos superiores aos do tratamento apenas com inoculação. Bahry et al. (2014) trabalhando com $\mathrm{N}$ na fase reprodutiva da soja verificaram a efeito positivo de 
alguns componentes de rendimento, no entanto, não houve aumento de produtividade.

Novo et al. (1999), utilizando $\mathrm{N}$ em cobertura, na forma de ureia, verificaram que houve contribuição para o incremento de produtividade da soja, entretanto, esses autores utilizaram soja no período de inverno ameno. Fipke et al. (2016) trabalhando com aplicação de $150 \mathrm{~kg}$ de $\mathrm{N} \mathrm{ha}^{-1}$, em cobertura na fase reprodutiva, verificaram aumento de $300 \mathrm{~kg}$ de grãos de soja em área com co-inoculação de Bradyrhizobium + Azospirillum brasilense na semente de soja. Marcon et al. (2017) verificaram para a cultura da soja que a aplicação de nitrogênio líquido, via foliar, suplementar na fase reprodutiva apresentou efeito na massa de mil grãos.

Este trabalho teve como objetivo verificar a resposta da soja inoculada com bactérias Bradyrhizobium japonicum e Bradyrhizobium elkanii, e com adubação nitrogenada suplementar na fase reprodutiva, via solo e via foliar.

\section{Desenvolvimento}

\subsection{Metodologia}

O experimento foi realizado no ano agrícola de 2017/2018, em um solo classificado como Latossolo Vermelho Distrófico, segundo o Sistema Brasileiro de Classificação de Solo (EMBRAPA, 2013) nas seguintes coordenadas: Latitude $19^{\circ} 28^{\prime} 36,40^{\prime}$ 'S e Longitude 54³8'47,27’O e Altitude de 720 m no município de São Gabriel do Oeste - MS. O clima da região é Aw, conforme classificação climática de Köppen, com chuvas no Verão e Inverno seco e temperatura média anual de $25{ }^{\circ} \mathrm{C}$. A precipitação média da região é de $1650 \mathrm{~mm}$ anuais

A área é utilizada para a agricultura, desde 1992, com a cultura da soja no período entre setembro a março e a cultura do milho após colheita da soja. O sistema adotado foi o convencional até o ano de 2000, após plantio direto, tendo o milheto como planta de cobertura.

O solo da área experimental apresentava na camada de 0 a $0,2 \mathrm{~m} \mathrm{pH}$ em água de 5,42, fósforo e potássio (Mehlich) 13,5 e 164,0 $\mathrm{mg} \mathrm{dm}^{-3}$, respectivamente, cálcio $3,4 \mathrm{cmol}_{+} \mathrm{dm}^{-3}$, magnésio $1,9 \mathrm{cmol}_{+} \mathrm{dm}^{-3}$ hidrogênio $7,2 \mathrm{cmol}_{+} \mathrm{dm}^{-3}$, matéria orgânica $37,6 \mathrm{~g} \mathrm{dm}^{-3}$, argila $560 \mathrm{~g} \mathrm{dm}^{-3}$, silte $8 \mathrm{~g} \mathrm{dm}^{-3}$ e areia total $432 \mathrm{~g} \mathrm{dm}^{-3}$.

Os tratamentos foram: testemunha (sem aplicação de $\mathrm{N}$ ), 30 e $60 \mathrm{~kg} \mathrm{~N} \mathrm{ha}^{-1}$ aplicados na fase R1 e R5.3, conforme escala proposta por Sediyama et al. (2015) via solo e aplicação via foliar com solução de 2\% de N em R1 e R5.3. A ureia com 45\% de $\mathrm{N}$, foi usada como fonte de $\mathrm{N}$, tanto para a via solo como via foliar. A aplicação da ureia via solo foi feita, manualmente, no meio do espaçamento da cultura. A aplicação foliar foi realizada dissolvendo 4,44 $\mathrm{kg}$ de ureia em $100 \mathrm{~L}$ de água e aplicado na parte aérea da soja com pulverizador manual pressurizado com $\mathrm{CO}_{2}$ regulado na vazão de $200 \mathrm{~L} \mathrm{ha}^{-1}$.

$\mathrm{Na}$ área antes da escolha das parcelas experimentais foi efetuada uma adubação básica de $80 \mathrm{~kg}$ de $\mathrm{P}_{2} \mathrm{O}_{5} \mathrm{ha}^{-1}$ e $80 \mathrm{~kg}$ de $\mathrm{K}_{2} \mathrm{O} \mathrm{ha}^{-1}$, utilizando como fonte a mistura granulada de 00 -
20-20, aplicado a lanço. Após, foram distribuídas sementes da cultivar Desafio, inoculadas com bactérias das espécies Bradyrhizobium japonicum e Bradyrhizobium elkanii (estirpes Semia 587 e Semia 5019), em sulcos espaçados de 0,45 m com 18 sementes por metro linear, através de semeadeira mecanizada.

Após 10 dias da semeadura, demarcaram-se as parcelas experimentais e os tratamentos distribuídos, segundo delineamento de blocos casualizados com quatro repetições, sendo a parcela constituída de quatro linhas de soja espaçadas de $0,45 \mathrm{~cm}$ com $5 \mathrm{~m}$ de comprimento $\left(9 \mathrm{~m}^{2}\right)$. Para a parcela útil, foram consideradas as duas linhas centrais com $1 \mathrm{~m}$ de bordadura nas extremidades totalizando uma área de $2,7 \mathrm{~m}^{2}$.

O manejo foi realizado em toda a área experimental, com aplicação de herbicida, fungicida e inseticida conforme o necessário. Não foram observados durante o período experimental anomalia em função de déficit hídrico no solo ou causados por injúria de insetos ou doenças.

Quando a planta atingiu o estádio R1 foi feita uma coleta de nódulos de $1 \mathrm{~m}$ linear de cada parcela. A retirada das plantas e raízes foi realizada com uma pá de ponta com cuidado para não perder volume de solo, e colocada em uma peneira com malha de $3 \mathrm{~mm}$ e aplicado água corrente para lavar o volume de solo. Na peneira foram retirados os nódulos para contagem e verificação através da cor de nódulos ativos ou inativos. A cor vermelha ou levemente arroxeada indicava nódulo ativo, e a cor esbranquiçada ou amarelada, inativo. Após colocados em sacos de papel e secos em estufa de circulação de ar forçado a $65{ }^{\circ} \mathrm{C}$, para obter a massa seca dos nódulos. A eficiência da nodulação foi obtida pela relação dos números de nódulos inativos pelo número totais de nódulos e extrapolados para percentagem $(\%)$.

No estádio R2 (pleno florescimento) foram retirados, de cada parcela, 10 folhas da parcela útil (folha índice para diagnóstico nutricional) de forma aleatória e uma por planta do $3^{\circ}$ nó a partir do ápice, de acordo com Kurihara et al. (2013) e determinado o teor de N, após digestão sulfúrica, pelo método Kjeldahl, conforme descrito em Embrapa (2011).

Após as plantas atingirem o estado de maturação fisiológica (R8) foi realizada a colheita de forma manual de toda a parcela útil, cortando a planta rente à superfície do solo. No material colhido foi medida a inserção da $1^{\circ}$ vagem, número de vagens, número de grãos por vagem, massa de toda a planta. Após, procedeu-se a debulha dos grãos de forma manual e se mediu a massa dos grãos e peso de 1000 grãos selecionados. Em ambas, as massas avaliadas foram corrigidas a umidade de $13 \%$ e a massa dos grãos extrapolado para $\mathrm{kg} \mathrm{ha}^{-1}$ para obter a produtividade.

O índice de colheita aparente foi obtido pela relação entre a massa de grãos e o somatório da massa de grãos, caules e vagens sem os grãos.

Após a colheita, amostras de terra de cada parcela foram encaminhadas para análise de fertilidade do solo, conforme 
Embrapa (2011), na camada de 0 a 0,2 m.

No período experimental ocorreu $683,60 \mathrm{~mm}$ de precipitação e temperatura máxima chegando a $37,0{ }^{\circ} \mathrm{C}$ com média de $30,69{ }^{\circ} \mathrm{C}$ e a temperatura mínima de $14,90{ }^{\circ} \mathrm{C}$ com média de 20,77 ${ }^{\circ} \mathrm{C}$ (Figura 1), valores obtidos da Estação Meteorológica de São Gabriel do Oeste (CEMTEC, 2018).

Figura 1 - Temperaturas máximas, mínimas e precipitação no período de 25 de setembro de 2015 a 25 de janeiro de 2016 , da estação meteorológica de São Gabriel do Oeste. ( $9.820 \mathrm{~m}$ da área experimental).

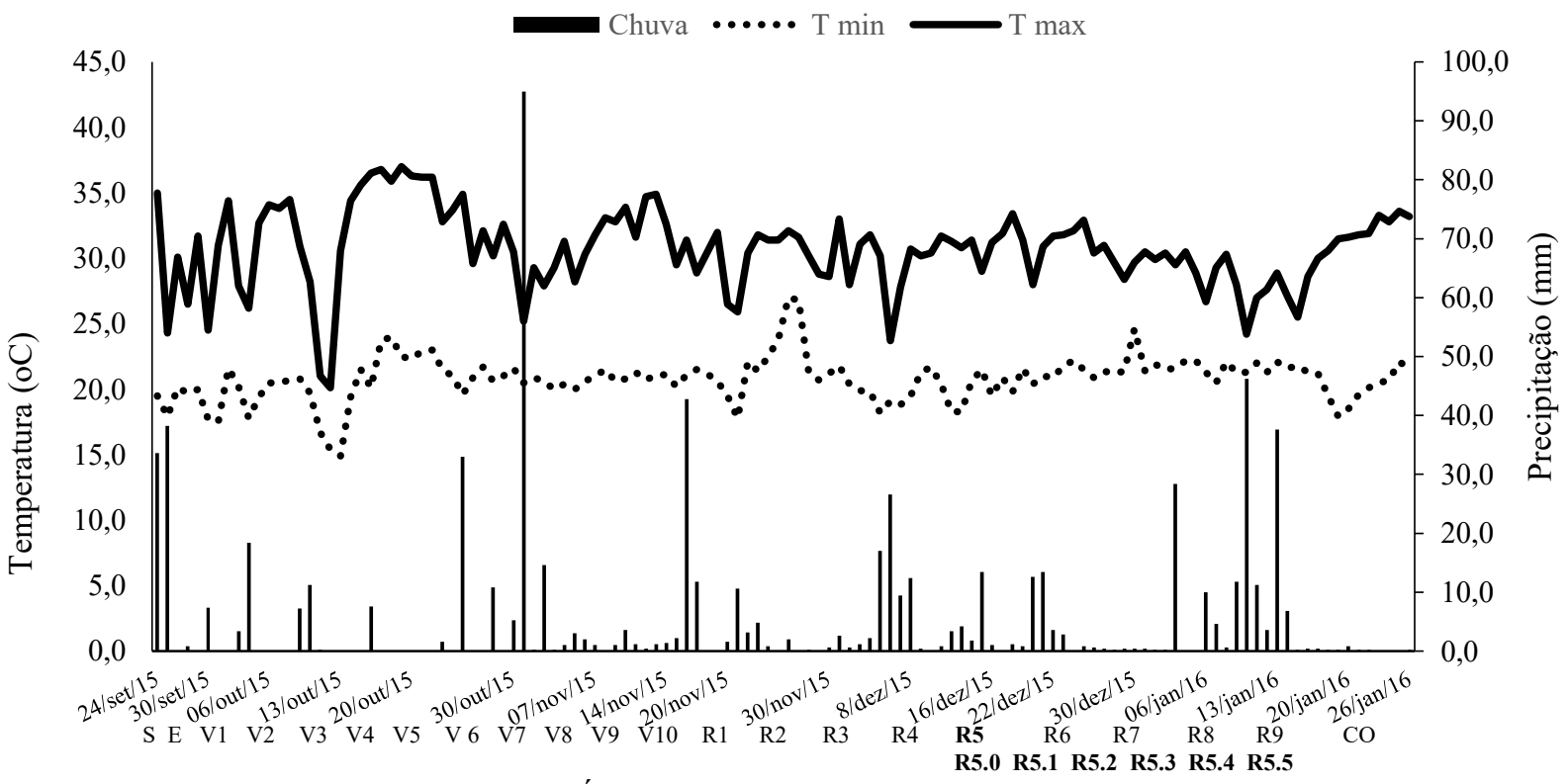

Épocas e Estádios fenológicos

$\mathrm{S}=$ semeadura, $\mathrm{E}=$ emergência, $\mathrm{V} 1, \mathrm{~V} 2 \ldots \mathrm{R} 1 . . \mathrm{R} 8$ = Estádios fenológicos e $\mathrm{CO}=$ Colheita.

Fonte: Adaptado de CEMTEC (2018).

Os dados foram submetidos à análise de variância e ao teste F. Após verificar a homogeneidade de variâncias e normalidade dos dados, teste de Duncan foi aplicado para comparar as médias e os dados, analisados no programa computacional SAS (Statistics Analyses Systems).

\subsection{Resultados e Discussão}

A adubação nitrogenada suplementar, quer seja via solo ou via foliar, não apresentou diferenças quanto à quantidade de nódulos ativos e totais, bem como a sua eficiência (Quadro 1). No trabalho foram observados que os valores médios de 54,12 nódulos totais, sendo 52,70 ativos e 4,46 não ativos, com eficiência de $91,47 \%$ e $0,34 \mathrm{~g} \mathrm{pl}^{-1}$ de massa seca de nódulos por planta.

Quadro 1 - Valores médios de nódulos ativos, não ativos, eficiência, peso seco no sistema radicular da soja em dois estágios fenológico e três formas de manejo da adubação nitrogenada.

\begin{tabular}{|c|c|c|c|c|c|c|}
\hline $\begin{array}{c}\text { Estádio } \\
\text { Fenológico }\end{array}$ & $\begin{array}{c}\mathbf{N ~ k g ~ h a - 1} e \\
\text { foliar }\end{array}$ & $\begin{array}{c}\text { Número de } \\
\text { Nódulos Ativos } \\
\text { (pl) }\end{array}$ & $\begin{array}{c}\text { Número de } \\
\text { Nódulos não ativos } \\
\text { (pl) }\end{array}$ & $\begin{array}{c}\text { Número de } \\
\text { Nódulos Totais } \\
\text { (pl) }\end{array}$ & Eficiência (\%) & $\begin{array}{l}\text { massa seca dos } \\
\text { nódulos }\left(\mathrm{g} \mathrm{pl}^{-1}\right)\end{array}$ \\
\hline Testemunha & 0 & $55,15 \mathrm{a}$ & $4,81 \mathrm{~b}$ & $59,96 \mathrm{a}$ & $91,98 \mathrm{a}$ & $0,35 \mathrm{~b}$ \\
\hline $\mathrm{R} 1$ & 30 & $54,73 \mathrm{a}$ & $3,78 \mathrm{~b}$ & $58,51 \mathrm{a}$ & $93,53 \mathrm{a}$ & $0,45 \mathrm{a}$ \\
\hline R1 & 60 & $51,08 \mathrm{a}$ & $3,95 \mathrm{~b}$ & $55,03 \mathrm{a}$ & $92,82 \mathrm{a}$ & $0,28 \mathrm{~b}$ \\
\hline R1 & 2 & $55,33 \mathrm{a}$ & $6,98 \mathrm{a}$ & $62,30 \mathrm{a}$ & $88,80 \mathrm{a}$ & $0,29 \mathrm{~b}$ \\
\hline R5 & 30 & $58,10 \mathrm{a}$ & $3,78 \mathrm{~b}$ & $61,88 \mathrm{a}$ & $93,90 \mathrm{a}$ & $0,33 \mathrm{~b}$ \\
\hline R5 & 60 & $51,10 \mathrm{a}$ & $4,42 \mathrm{~b}$ & $55,52 \mathrm{a}$ & $92,04 \mathrm{a}$ & $0,30 \mathrm{~b}$ \\
\hline R5 & 2 & $53,40 \mathrm{a}$ & $3,54 \mathrm{~b}$ & $56,94 \mathrm{a}$ & $93,78 \mathrm{a}$ & $0,38 \mathrm{~b}$ \\
\hline \multicolumn{2}{|c|}{ Média } & 52,70 & 4,46 & 54,13 & 91,47 & 0,34 \\
\hline \multicolumn{2}{|c|}{$\mathrm{CV}$} & 22,47 & 26,54 & 23,12 & 18,42 & 32,45 \\
\hline \multicolumn{2}{|c|}{ Teste F } & $1,24^{\mathrm{ns}}$ & $3,15^{*}$ & $0,85^{\mathrm{ns}}$ & $1,44^{\mathrm{ns}}$ & $4,24^{*}$ \\
\hline \multicolumn{2}{|c|}{ DMS } & 5,22 & 1,82 & 7,55 & 8,67 & 0,18 \\
\hline
\end{tabular}

${ }_{\text {ns }}=$ não significativo $e^{*}$ significativo a $5 \%$ de probabilidade. Médias seguidas pela mesma letra na coluna, diferem entre si pelo teste de Duncan a $5 \%$ de probabilidade. Inclui $\mathrm{p} 1=$

Fonte: Dados da pesquisa. 
A nodulação da cultura no experimento pode ser considerada adequada, quando comparados aos obtidos por Sartori et al. (2015), que verificaram valores de 65,7 nódulos por planta e 5,4 nódulos inativos por planta, proporcionado uma eficiência de $92,2 \%$ e atingindo produtividades de $3.750 \mathrm{~kg} \mathrm{ha}^{-1}$.

A eficiência da inoculação também pode ser observada nos valores dos teores foliares, que indica o estado nutricional da planta. Não foi verificado efeito para $\mathrm{N}, \mathrm{P}$, $\mathrm{K}, \mathrm{Ca}, \mathrm{Mg}$ e S (Quadro 2). Comparando estes valores com os indicados por Kurihara et al. (2013) verificamos que $\mathrm{N}$ e $\mathrm{K}$ estavam adequados e $\mathrm{P}, \mathrm{Ca}, \mathrm{Mg}$ e $\mathrm{S}$ estavam em média $10 \%$ abaixo, demonstrando que a cultura apresentava em bom estado nutricional, antes da aplicação do nitrogênio na fase reprodutiva. Ainda, considerando os dados de Kurihara et al. (2013), os micronutrientes apresentaram diferenças significativas, no entanto, os valores estavam acima da necessidade da planta, com exceção do Mn que ficou abaixo da necessidade, fato atribuído aos altos valores de ferro encontrado nas folhas que pode ter influenciado a absorção do Mn por inibição competitiva.

Quadro 2 - Valores médios dos teores de nutrientes no tecido foliar da soja em dois estágios fenológico e três formas de manejo da adubação nitrogenada em cobertura na cultura da soja

\begin{tabular}{|c|c|c|c|c|c|c|c|c|c|c|c|c|}
\hline \multirow{2}{*}{$\begin{array}{c}\text { Estádio } \\
\text { Fenológico }\end{array}$} & \multirow{2}{*}{$\begin{array}{c}\mathrm{N} \mathrm{kg} \mathrm{ha}^{-1} \\
\text { e foliar } \\
\end{array}$} & $\mathrm{N}$ & $\mathrm{P}$ & $\mathrm{K}$ & $\mathrm{Ca}$ & $\mathrm{Mg}$ & $\mathrm{S}$ & $\mathrm{Fe}$ & $\mathrm{Mn}$ & $\mathrm{Zn}$ & $\mathrm{Cu}$ & $\mathrm{B}$ \\
\hline & & \multicolumn{6}{|c|}{ - - - - - - - - $\mathrm{g} \mathrm{kg}^{-1} \ldots-\ldots-\cdots$} & \multicolumn{5}{|c|}{$-\ldots-\ldots \mathrm{mg} \mathrm{kg}^{-1}-\ldots \ldots$} \\
\hline Test & 0 & $35 \mathrm{a}$ & $2,51 \mathrm{a}$ & $20,00 \mathrm{a}$ & $7,52 \mathrm{a}$ & $2,45 \mathrm{a}$ & $1,61 \mathrm{a}$ & $25 \mathrm{~b}$ & $27,64 \mathrm{a}$ & $37,44 \mathrm{~b}$ & $64,51 \mathrm{a}$ & $91,83 \mathrm{a}$ \\
\hline $\mathrm{R} 1$ & 30 & $1,91 \mathrm{a}$ & $2,84 \mathrm{a}$ & $19,75 \mathrm{a}$ & $8,22 \mathrm{a}$ & $67 \mathrm{a}$ & $1,70 \mathrm{a}$ & $814,71 \mathrm{a}$ & $35,98 \mathrm{a}$ & $63,22 \mathrm{a}$ & $15,62 \mathrm{~b}$ & $70,78 \mathrm{a}$ \\
\hline $\mathrm{R} 1$ & 60 & $06 \mathrm{a}$ & $2,62 \mathrm{a}$ & $21,00 \mathrm{a}$ & $7,63 \mathrm{a}$ & $4 \mathrm{a}$ & $1,67 \mathrm{a}$ & $96 \mathrm{~b}$ & $27,64 \mathrm{a}$ & $33,22 b$ & 9 & $71,88 \mathrm{a}$ \\
\hline $\mathrm{R}$ & $\%$ & $5 \mathrm{a}$ & $55 \mathrm{a}$ & $20,25 \mathrm{a}$ & $\mathrm{a}$ & $\mathrm{a}$ & $5 \mathrm{a}$ & $1 \mathrm{~b}$ & $32,09 \mathrm{a}$ & $2 \mathrm{~b}$ & $8 \mathrm{~b}$ & $88 \mathrm{a}$ \\
\hline $\mathrm{R}$ & 30 & $3 \mathrm{a}$ & $2,38 \mathrm{a}$ & $18,75 \mathrm{a}$ & $\mathrm{a}$ & & $3 \mathrm{a}$ & $49 \mathrm{~b}$ & $25,41 \mathrm{a}$ & $29,69 \mathrm{~b}$ & $7 \mathrm{~b}$ & $79,87 \mathrm{a}$ \\
\hline $\mathrm{R}$ & 60 & $77 \mathrm{a}$ & $2,48 \mathrm{a}$ & $19,50 \mathrm{a}$ & $7,63 \mathrm{a}$ & $2,65 \mathrm{a}$ & $1,96 \mathrm{a}$ & $466,67 \mathrm{~b}$ & $24,86 \mathrm{a}$ & $30,54 \mathrm{~b}$ & $9,07 \mathrm{~b}$ & $82,50 \mathrm{a}$ \\
\hline $\mathrm{R}$ & $\%$ & $2,75 \mathrm{a}$ & $2,76 \mathrm{a}$ & $21,50 \mathrm{a}$ & $7,91 \mathrm{a}$ & $2,69 \mathrm{a}$ & $2,17 \mathrm{a}$ & $447,06 \mathrm{~b}$ & $27,08 \mathrm{a}$ & $28,42 \mathrm{~b}$ & $8,57 \mathrm{~b}$ & $74,33 \mathrm{a}$ \\
\hline \multicolumn{2}{|c|}{$\mathrm{CV}$} & 9,51 & 11,24 & 10,15 & 12,42 & 9,37 & 17 & 15,77 & 13,22 & 12,47 & 56 & 11,24 \\
\hline \multicolumn{2}{|c|}{ Teste F } & $1,85^{\mathrm{ns}}$ & $1,25^{\mathrm{ns}}$ & $1,98^{\mathrm{ns}}$ & $2,05^{\mathrm{ns}}$ & $1,65^{\mathrm{ns}}$ & $2,16^{\mathrm{ns}}$ & $3,95^{*}$ & $1,73^{\mathrm{ns}}$ & $4,58 * *$ & $7,85^{* *}$ & $2,07^{\text {ns }}$ \\
\hline \multicolumn{2}{|c|}{ DMS } & 9,32 & 0,71 & 2,83 & 1,34 & 0,41 & 0,62 & 215,04 & 11,67 & 12,36 & 17,54 & 23,77 \\
\hline
\end{tabular}

significativo $\mathrm{e}^{*} \mathrm{e} * *$ respectivamente significativo a $5 \%$ e $1 \%$ de probabilidade. Médias seguidas pela mesma letra na coluna, diferem entre $\mathrm{s} i$ pelo teste de Duncan a $5 \%$ de probabilidade.

Fonte: Dados da pesquisa

$\mathrm{Na}$ análise de biometria da parte aérea da planta, aqui considerada como a inserção da $1^{\mathrm{a}}$ vagem, o número de vagem por planta e o número de grão por vagem, não foram afetadas pelos tratamentos, provavelmente, pelo fato destes parâmetros já terem sido definidos antes do estádio R1 da cultura
(Quadro 3) e o genótipo da planta. Procópio et al. (2014) comentaram sobre estas biometrias da planta de soja, sendo mais influenciadas pelo genótipo e a interação do ambiente e não pela adubação e ou população de plantas, confirmado no trabalho de Balbinot Júnior et al. (2015).

Quadro 3 - Valores médios para inserção da $1^{\text {a }}$ vagem, número de vagem e grãos por vagem na planta de soja em dois estágios fenológico e três formas de manejo da adubação nitrogenada

\begin{tabular}{|c|c|c|c|c|}
\hline Estádio Fenológico & N kg ha ${ }^{-1}$ e Foliar & $\begin{array}{l}\text { Altura Inserção da } 1^{\mathrm{a}} \\
\text { Vagem (cm) }\end{array}$ & Número de Vagem (pl) & $\begin{array}{c}\text { Número de Grãos por } \\
\text { Vagem }\end{array}$ \\
\hline Testemunha & 0 & $13,50 \mathrm{a}$ & $37,63 \mathrm{a}$ & $2,42 \mathrm{a}$ \\
\hline $\mathrm{R} 1$ & 30 & $14,20 \mathrm{a}$ & $41,60 \mathrm{a}$ & $2,40 \mathrm{a}$ \\
\hline $\mathrm{R} 1$ & 60 & $11,38 \mathrm{a}$ & $38,23 \mathrm{a}$ & $2,30 \mathrm{a}$ \\
\hline R1 & $2 \%$ & $14,63 \mathrm{a}$ & $39,73 \mathrm{a}$ & $2,33 \mathrm{a}$ \\
\hline R5 & 30 & $14,25 \mathrm{a}$ & $37,48 \mathrm{a}$ & $2,28 \mathrm{a}$ \\
\hline R5 & 60 & $12,63 \mathrm{a}$ & $44,15 \mathrm{a}$ & $2,50 \mathrm{a}$ \\
\hline R5 & $2 \%$ & $13,00 \mathrm{a}$ & $42,90 \mathrm{a}$ & $2,28 \mathrm{a}$ \\
\hline \multicolumn{2}{|c|}{$\mathrm{CV}$} & 18,26 & 12,35 & 13,71 \\
\hline \multicolumn{2}{|c|}{ Teste $\mathrm{F}$} & $1,44^{\mathrm{ns}}$ & $1,09^{\mathrm{ns}}$ & $1,22^{\mathrm{ns}}$ \\
\hline \multicolumn{2}{|c|}{ DMS } & 3,85 & 7,58 & 0,47 \\
\hline
\end{tabular}

ns = não significativo. Médias seguidas pela mesma letra na coluna, não diferem entre si pelo teste de Duncan a $5 \%$ de probabilidade.

Fonte: dados da pesquisa.

A massa de 1000 grãos não foi afetada pelos tratamentos e a produtividade foi significativa para os tratamentos com 60 $\mathrm{kg}$ de $\mathrm{N}_{\text {ha }}{ }^{-1}$ aplicados nos estádios de R1 e R5.3. No índice de colheita, o tratamento com $60 \mathrm{~kg}$ de $\mathrm{N} \mathrm{ha}^{-1} \mathrm{em} \mathrm{R} 1$ foi superior aos demais, inclusive ao $60 \mathrm{~kg}$ de $\mathrm{N} \mathrm{ha}^{-1}$ em R5.3. Considerando os tratamentos via foliar, ou seja, aplicação de solução de $2 \%$ de N em R1 e R5.3, houve efeito em relação à testemunha para produtividade de grãos e índice de colheita (Quadro 4). 
Quadro 4 - Valores médios para peso de 100 grãos e produtividade para a cultura da soja em dois estágios fenológico e três formas de manejo da adubação nitrogenada

\begin{tabular}{|c|c|c|c|c|}
\hline Estádio Fenológico & N kg ha-1 e foliar & $\begin{array}{l}\text { Massa de } 1000 \text { grãos } \\
(\mathrm{g})\end{array}$ & $\begin{array}{l}\text { Produtividade } \\
\left(\mathrm{kg} \mathrm{ha}^{-1}\right)\end{array}$ & Índice de colheita \\
\hline Testemunha & 0 & $145,19 \mathrm{a}$ & $3.740,8 \mathrm{~b}$ & $0,482 \mathrm{c}$ \\
\hline $\mathrm{R} 1$ & 30 & $148,33 \mathrm{a}$ & $3.632,2 \mathrm{~b}$ & $0,479 \mathrm{c}$ \\
\hline $\mathrm{R} 1$ & 60 & $150,14 \mathrm{a}$ & $4.219,4 \mathrm{a}$ & $0,498 \mathrm{a}$ \\
\hline $\mathrm{R} 1$ & $2 \%$ & $152,46 \mathrm{a}$ & $3.762,5 \mathrm{~b}$ & $0,480 \mathrm{c}$ \\
\hline R5 & 30 & $145,27 \mathrm{a}$ & $3.877,2 \mathrm{~b}$ & $0,487 \mathrm{c}$ \\
\hline R5 & 60 & $145,95 \mathrm{a}$ & $4.213,6 \mathrm{a}$ & $0,493 \mathrm{~b}$ \\
\hline R5 & $2 \%$ & $149,77 \mathrm{a}$ & $3.605,0 \mathrm{~b}$ & $0,479 \mathrm{~d}$ \\
\hline \multicolumn{2}{|c|}{$\mathrm{CV}$} & 17,64 & 15,43 & 9,37 \\
\hline \multicolumn{2}{|c|}{ Teste F } & $1,95^{\mathrm{ns}}$ & $6,47^{*}$ & $5,85^{*}$ \\
\hline \multicolumn{2}{|c|}{ DMS } & 9,72 & 297,92 & 0,003 \\
\hline
\end{tabular}

ns = não significativo $\mathrm{e}^{*}$ significativo a $5 \%$ de probabilidade. Médias seguidas pela mesma letra na coluna não diferem entre si pelo teste de Duncan a $5 \%$ de probabilidade.

Fonte: Dados da pesquisa.

O índice de colheita, como é uma relação da massa de grãos pela massa seca de toda a planta, está associado ao índice de área foliar que permite a interceptação da radiação fotossintética ativa. Nem sempre toda a luz interceptada pela área foliar é convertida em fitomassa e, consequentemente, maior produtividade de grãos. Assim, o índice de colheita expressa a eficiência da cultura em converter fitomassa em produtividade de grãos, que neste trabalho apresentou a mesma tendência com a produtividade de grãos, mas não com a massa de 1000 grãos.

A aplicação de $60 \mathrm{~kg}$ de $\mathrm{N} \mathrm{ha}^{-1}$, tanto em R1 como em R5.3, proporcionou aumento na produtividade de grãos de 478,6 kg ha ${ }^{-1}$ e $472,8 \mathrm{~kg} \mathrm{ha}^{-1}$, respectivamente em R1 e R5.3, devendo ser considerado o custo do produto e a aplicação, para verificar a viabilidade econômica. A aplicação tardia de $\mathrm{N}$, na cultura da soja, deve-se levar na avaliação, tanto o manejo adotado quanto as condições edafoclimáticas, no momento da aplicação que terão influência na produtividade da cultura da soja.

$\mathrm{Na}$ avaliação da fertilidade do solo, realizada na época imediatamente após a colheita, foi observado que os níveis de fósforo, (média de $3 \mathrm{mg} \mathrm{dm}^{-3}$ ) estavam abaixo do recomendado (Quadro 5), quando comparados aos níveis críticos de P no solo, sendo que Vieira et al. (2015) recomendaram valores de $8 \mathrm{mg} \mathrm{dm}^{-3}$.

Quadro 5 - Valores médios dos atributos químicos no solo, para fins de fertilidade no cultivo de soja em dois estágios fenológico e três formas de manejo da adubação nitrogenada

\begin{tabular}{|c|c|c|c|c|c|c|c|c|c|}
\hline \multirow{2}{*}{$\begin{array}{c}\text { Estágio } \\
\text { Fenológico }\end{array}$} & \multirow{2}{*}{$\begin{array}{c}\mathrm{N} \mathrm{kg} \mathrm{ha}^{-1} \mathrm{e} \\
\text { foliar }\end{array}$} & \multicolumn{2}{|c|}{$\mathbf{p H}$} & $\mathbf{P}$ & $\mathbf{K}$ & $\mathbf{C a}$ & Mg & $\mathbf{H}$ & \multirow{2}{*}{$\begin{array}{c}\text { MO } \\
\mathrm{g} \mathrm{dm}^{-3} \\
\end{array}$} \\
\hline & & água & $\mathrm{CaCl}_{2}$ & \multicolumn{2}{|c|}{ - - -mg dm ${ }^{-3}-\cdots$} & \multicolumn{3}{|c|}{$-\cdots---\mathrm{cmol}_{+} \mathrm{dm}^{-3}-\ldots$} & \\
\hline Testemunha & 0 & $5,47 \mathrm{a}$ & $4,57 \mathrm{a}$ & $3,23 \mathrm{a}$ & $170 \mathrm{a}$ & $3,50 \mathrm{a}$ & $1,85 \mathrm{a}$ & $6,81 \mathrm{a}$ & $40,38 \mathrm{a}$ \\
\hline $\mathrm{R} 1$ & 30 & $5,35 \mathrm{ab}$ & $4,45 \mathrm{ab}$ & $3,03 \mathrm{a}$ & $198 \mathrm{a}$ & $2,95 \mathrm{a}$ & $2,03 \mathrm{a}$ & $7,89 \mathrm{a}$ & $36,59 \mathrm{a}$ \\
\hline R1 & 60 & $5,30 \mathrm{~b}$ & $4,43 \mathrm{ab}$ & $3,59 \mathrm{a}$ & $190 \mathrm{a}$ & $3,38 \mathrm{a}$ & $1,73 \mathrm{a}$ & $6,87 \mathrm{a}$ & $31,02 \mathrm{a}$ \\
\hline R1 & $2 \%$ & $5,52 \mathrm{a}$ & $4,62 \mathrm{a}$ & $5,41 \mathrm{a}$ & $180 \mathrm{a}$ & $3,68 \mathrm{a}$ & $1,85 \mathrm{a}$ & $6,32 \mathrm{a}$ & $39,26 \mathrm{a}$ \\
\hline $\mathrm{R} 5$ & 30 & $5,27 \mathrm{~b}$ & $4,41 \mathrm{ab}$ & $2,78 \mathrm{a}$ & $170 \mathrm{a}$ & $3,35 \mathrm{a}$ & $1,93 \mathrm{a}$ & $6,39 \mathrm{a}$ & $38,96 \mathrm{a}$ \\
\hline R5 & 60 & $5,23 \mathrm{~b}$ & $4,34 \mathrm{~b}$ & $3,31 \mathrm{a}$ & $118 \mathrm{a}$ & $3,30 \mathrm{a}$ & $2,28 \mathrm{a}$ & $9,54 \mathrm{a}$ & $37,11 \mathrm{a}$ \\
\hline R5 & $2 \%$ & $5,46 \mathrm{a}$ & $4,56 \mathrm{a}$ & $3,58 \mathrm{a}$ & $128 \mathrm{a}$ & $3,48 \mathrm{a}$ & $1,75 \mathrm{a}$ & $6,42 \mathrm{a}$ & $40,08 \mathrm{a}$ \\
\hline \multicolumn{2}{|c|}{$\mathrm{CV}$} & 15,22 & 16,14 & 13,79 & 12,47 & 16,52 & 18,26 & 14,75 & 19,33 \\
\hline \multicolumn{2}{|c|}{ Teste $\mathrm{F}$} & $3,73 *$ & $6,52 *$ & $1,77^{\mathrm{ns}}$ & $2,03^{\mathrm{ns}}$ & $1,94^{\mathrm{ns}}$ & $2,11^{\mathrm{ns}}$ & $1,67^{\mathrm{ns}}$ & $2,18^{\mathrm{ns}}$ \\
\hline \multicolumn{2}{|c|}{ DMS } & 0,21 & 0,19 & 2,67 & 75,2 & 0,86 & 0,83 & 3,74 & 9,84 \\
\hline
\end{tabular}

ns = não significativo e * significativo a $5 \%$ de probabilidade. Médias seguidas pela mesma letra na coluna, não diferem entre si pelo teste de Duncan a $5 \%$ de probabilidade.

Fonte: Dados da pesquisa.

Este fato pode ter limitado a resposta da cultura, principalmente, na dose de $30 \mathrm{~kg}$ de $\mathrm{N} \mathrm{ha}^{-1}$ e na aplicação via foliar. Os demais parâmetros da fertilidade do solo foram considerados adequados para a cultura da soja.

\section{Conclusão}

A aplicação tardia de N, via solo ou foliar, em R1 ou em R5.3, não proporciona aumento na produtividade de grãos para a cultivar de soja Desafio inoculada com bactérias
Bradyrhizobium japonicum e Bradyrhizobium elkanii. A aplicação de N, via solo, em R1 apresenta melhor índice de colheita, mas não tem influência na produtividade da cultura.

\section{Referências}

BAHRY, C.A. et al. Efeito do nitrogênio suplementar sobre os componentes de rendimento da soja em condição de estresse hídrico. Rev. Ceres. v.61, n.2, p.288-292, 2014. doi: 10.1590/ S0034-737X2014000200019. 
BALBINOT JÚNIOR, A.A. et al. Semeadura cruzada em cultivares de soja com tipo de crescimento determinado. Semina: Ciênc. Agrárias, v.36, p.1215-1226, 2015. doi:10.5433/16790359.2015v36n3p1215

CEMTEC - Centro de monitoramento de Tempo, do Clima e dos Recursos Hídricos de Mato Grosso do Sul, Campo Grande - MS. Disponível em: https://www.cemtec.ms.gov.br/boletinsmeteorologicos/ Acesso em: 22 jan. 2020.

EMBRAPA - Empresa Brasileira de Pesquisa Agropecuária, Sistema Brasileiro de Classificação de Solos. Brasília: Embrapa, 2013.

EMBRAPA - Empresa Brasileira de Pesquisa Agropecuária. Manual de análises química de solos, plantas e fertilizantes, Brasília: Embrapa, 2011.

FIPKE, G. M. et al. Co-inoculation with diazotrophic bacteria in soybeans associated to urea topdressing. Ciênc. Agrotecnol., v.40, n.5, p.522-533, 2016. doi: 10.1590/1413-70542016405001316.

FRANCHINI, J. C. et al. Desempenho da soja em consequência de manejo de pastagem, época de dessecação e adubação nitrogenada. Pesq. Agropec. Bras., v.50, n.12, p.1131-1138, 2015. doi: 10.1590/S0100-204X2015001200002

HUNGRIA, M. et al. Contribution of biological nitrogen fixation to the $\mathrm{N}$ nutrition of grain crops in the tropics: the success of soybean (Glycine max(L.) Merr.) in South America. In: SINGH, R.P.; SHANKAR, N.; JAIWAL, P.K. Nitrogen nutrition and sustainable plant productivity. Houston: Studium, 2006.

KURIHARA, C. H. et al. Acúmulo de matéria seca e nutrientes em soja, como variável do potencial produtivo. Rev. Ceres, v.60, n.5, p.690-698, 2013.

MAEHLER, A. R. et al. Qualidade de grãos de duas cultivares de soja em função da disponibilidade de água no solo e arranjo de plantas. Ciênc. Rural, v.33, p.213-218, 2003.

MARCON, E.C. et al. Uso de diferentes fontes de nitrogênio na cultura da soja. Rev. Thema, v.14, p.298-308. 2017. doi: 10.15536/ thema.14.2017.298-308.427
MENDES, I. DE C. et al. Adubação nitrogenada suplementar tardia em soja cultivada em latossolos do Cerrado. Pesq. Agropec. Bras., v.43, n.8, p.1053-1060, 2008.

NOVO, M. C. S. S. et al. Nitrogênio e potássio na fixação simbiótica de $\mathrm{N}_{2}$ por soja cultivada no inverno. Scie. Agricola, v.56, n.1, p.143-156, 1999.

PETTER, F.A. et al. Elevada densidade de semeadura aumenta a produtividade da soja? Respostas da radiação fotossinteticamente ativa. Bragantia, v.75, n.2, p.173-183, 2016. doi: 10.1590/16784499.447

PROCÓPIO, S.O. et al. Semeadura em fileira dupla e espaçamento reduzido na cultura da soja. Rev. Agroamb., v.8, p.212-221, 2014. doi: 10.18227/1982-8470ragro.v8i2.1469

SARTORI, G.M.S. et al. Rendimento de grãos de soja em função de sistemas de plantio e irrigação por superfície em Planossolos. Pesq. Agropec. Bras., v.50, n.12, p.1139-1149, 2015.

SEDIYAMA, T.; SILVA, F.; BORÉM, A. Soja: do plantio à colheita. Viçosa: Universidade Federal de Viçosa, 2015.

SILVA, W.B. et al. Desenvolvimento inicial de Urochloa ruziziensis e desempenho agronômico da soja em diferentes arranjos espaciais no cerrado Mato-Grossense. Bragantia, v.72, p.146-153, 2013.

VIEIRA, R.C.B. et al. Adubação fosfatada para alta produtividade de soja, milho e cereais de inverno cultivados em rotação em latossolos em plantio direto no Centro-Sul do Paraná. Rev. Bras. Ciênc. Solo, v. 39, n.3, p.794-808, 2015. doi: $10.1590 / 01000683$ rbcs20140463

WERNER, F. et al. Soybean growth affected by seeding rate and mineral nitrogen. Rev. Bras. Eng. Agric. Amb., v.20, n.8, p.734738, 2016. doi: 10.1590/1807-1929/agriambi.v20n8p734-738.

ZILLI, J.É. et al. Inoculação da soja com Bradyrhizobium no sulco de semeadura alternativamente à inoculação de sementes. Rev. Bras. Ciênc. Solo, v.34, n.6, p.1875-188, 2010. doi: 10.1590/ S0100-06832010000600011. 